This item was submitted to Loughborough's Research Repository by the author.

Items in Figshare are protected by copyright, with all rights reserved, unless otherwise indicated.

\title{
Enhanced ultrasonically assisted turning of a $\beta$-titanium alloy
}

PLEASE CITE THE PUBLISHED VERSION

http://dx.doi.org/10.1016/j.ultras.2013.03.006

\section{PUBLISHER}

(C) Elsevier B.V.

\section{VERSION}

AM (Accepted Manuscript)

\section{LICENCE}

CC BY-NC-ND 4.0

\section{REPOSITORY RECORD}

Maurotto, Agostino, Riaz Muhammad, Anish Roy, and Vadim V. Silberschmidt. 2019. "Enhanced Ultrasonically Assisted Turning of a B-titanium Alloy”. figshare. https://hdl.handle.net/2134/12140. 
This item was submitted to Loughborough's Institutional Repository (https://dspace.lboro.ac.uk/) by the author and is made available under the following Creative Commons Licence conditions.

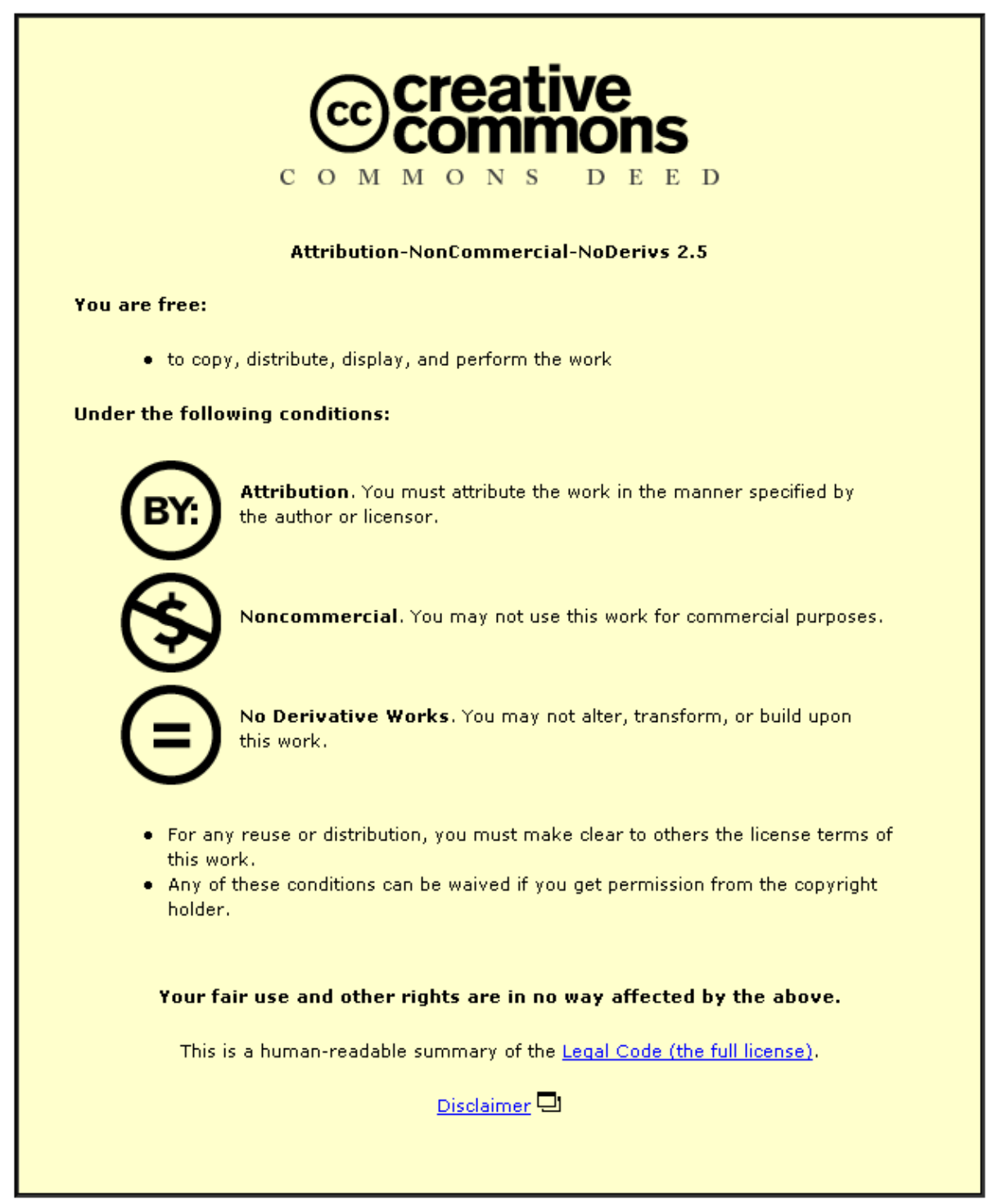

For the full text of this licence, please go to: http://creativecommons.org/licenses/by-nc-nd/2.5/ 


\section{Enhanced ultrasonically assisted turning of a $\beta$-titanium alloy}

Agostino Maurotto, Riaz Muhammad, Anish Roy ${ }^{*}$, Vadim V. Silberschmidt

Wolfson School of Mechanical and Manufacturing Engineering, Loughborough University, Loughborough, Leicestershire LE11 3TU, UK

*Corresponding author Tel.: +44 1509 227637; fax: +44 1509227648.

Email: A.Roy3@lboro.ac.uk

\section{Abstract:}

Although titanium alloys have outstanding mechanical properties such as high hot hardness, a good strength-to-weight ratio and high corrosion resistance; their low thermal conductivity, high chemical affinity to tool materials severely impair their machinability. Ultrasonically assisted machining (UAM) is an advanced machining technique, which has been shown to improve machinability of a $\beta$ titanium alloy, namely, Ti-15-3-3-3, when compared to conventional turning processes.

Keywords: Ultrasonically assisted machining; turning; ultrasonic vibration

\section{Introduction}

Machining of titanium alloys has been identified as one of the most important manufacturing processes since broad adoption of these alloys in aerospace, automotive, chemical and biomedical industries [1]. Titanium alloys have excellent mechanical properties such as high hot hardness, a good strength-to-weight ratio and high corrosion resistance. It is also well known that $\beta$-titanium alloys offer higher tensile strengths due to their enhanced inherent hardness, with increased fatigue strength and better forming properties in comparison to near- $\alpha-$ or $\alpha+\beta$-titanium alloys. However, poor thermal conductivity and high chemical affinity of these alloys to traditional tool materials 
severely impair their machinability [2]. It has been reported that $\beta$-titanium alloys are among the most difficult to machine titanium alloys [3].

Machining processes of titanium alloys are typically characterized by low cutting feeds and speeds, typically in the range of 12 to $38 \mathrm{~m} / \mathrm{min}$ for aged alloys [4]. This increases machining costs, especially for many aircraft components where $90 \%$ of the material often needs to be removed in order to achieve a final shape. Needless to say, the cost of machined titanium components could be substantially reduced by improving material removal rates (MRR). Additionally, high friction at the flank and rake faces of the tool leads to localized high-temperature zones at the tool-chip interface, accelerating tool wear and eventually causing premature tool failure [5]. A use of cutting fluids for cooling and lubrication is typically recommended in the machining of titanium alloys to avoid rapid tool wear [6]. Their primary goal is to dissipate generated heat from the work-piece and the machine tool thus avoiding rapid localized thermal expansions at the tool tip. Also, the lubricant reduces friction at the tool-work-piece interface improving machining efficiency.

In recent years, costs of machining involving the use of cutting fluids have increased substantially, primarily due to environmental concerns: the handling of cutting fluids as well as their disposal must obey strict rules of environmental protection. For manufacturing companies, the costs related to cutting fluids represent a large amount of the total machining costs, with some researchers having claimed that the costs related to cutting fluids are higher than the cost of cutting tools [7]. Byrne and Scholta [8] showed that the cutting-fluid technology made up a significant portion of manufacturing costs, with additional costs incurred in time-consuming cleaning of components post manufacture due to cutting fluid residuals. Consequently, elimination of cutting fluids, if possible, can be a significant economic incentive.

Thus, dry machining attracts great interest since it addresses current needs for environmentally friendly manufacturing as an appropriate alternative to conventional machining with flood cuttingfluid supply [9]. Mativenga and Rajemi [10] noted that dry machining compared favourably in 
reducing the energy footprint of machined products, since up to $9 \%$ of the total machining power is typically spent alone on pumping coolants. Elimination of lubricants and coolants presents some additional challenges in machining of difficult-to-cut materials. Well-known negative effects, in addition to rapid tool wear, are generation of high cutting forces, poor surface finish and, ultimately, poor dimensional accuracy of a finished component [11]. As a result, several finishing steps need to be incorporated into a manufacturing process in order to obtain the desired component quality, increasing the overall machining cost.

Vibration-assisted machining, though well known for several decades, has recently been introduced commercially, by DMG-Mori Seiki (a first version launched in 2006). The working principle of a vibration-assisted machining process is based on subjecting a tool to high-frequency vibration with a specific intensity and in a specific direction during the machining process. The specific features of material behaviour when subjected to ultrasonic fields are well known as was demonstrated in various experiments over the years. Amongst these features is a drastic change of elastic-plastic behaviour of the work-piece material and of contact conditions, where dry friction in the region of interactions between two surfaces transforms into quasi-viscous friction in the presence of ultrasonic vibration [12]. An acoustic softening effect, where an apparent static shear stress necessary for plastic deformation is significantly reduced under intense ultrasonic excitation, was observed in several metals including titanium since its discovery in $\mathrm{Zn}$ crystals [13]. It is believed that acoustic energy is absorbed by dislocations and grain-boundaries, enhancing plastic deformation [14], since little attenuation was observed in defect-free regions.

Babitsky and co-workers $[12,15,16]$ reported on several well-documented advantages of ultrasonically assisted machining processes of intractable alloys such as drilling [15] and turning [16]. With respect to turning operations, ultrasonically assisted turning (UAT) has been used to demonstrate a range of benefits in machining of intractable materials. One of its major advantages is reduction of average cutting forces in the presence of vibration. Babitsky et al. [16] and Sharman et 
al. [17] demonstrated that the effect was pronounced when the vibration was in the direction of cut with force reductions in excess of $50 \%$. When compared to dry conventional turning (CT), the surface finish of the work-piece was observed to improve with an associated reduction in machine noise or chatter during operation as demonstrated in $[12,18]$. Several studies were performed on underlying mechanics of cutting under ultrasonic vibrations, which helped to elucidate features of the machining process with respect to material behaviour under high-strain, high-strain-rate regimes [19-22]. Muhammad et al. [19] developed a thermo-mechanically coupled finite element model of UAT building on prior modelling work [20], which elucidated the effect of micro-impacting in a process zone in UAT on machining of intractable alloys.

Generally, realisation of UAT process with its discussed benefits is sensitive to cutting parameters (depth of cut, cutting speed, feed rate, etc.) as well as to a work-piece material and cutting tool used. In this paper, an enhanced UAT system is presented, which has been used to machine a $\beta$-Ti alloy demonstrating improvements not previously reported.

The paper is organised as follows: in Section 2, a description of the experimental setup including various characterisation instruments used are presented along with details of the work-piece material and cutting tools used. Section 3 comprises the measurement results followed by discussions in Section 4. The paper ends with some concluding remarks in Section 5.

\section{Experimental Work}

\subsection{Experimental Setup}

A universal lathe was adequately modified to accommodate an ultrasonic cutting head with flexibility of switching between conventional and ultrasonic cutting regimes during a single turning operation. The cutting head consists of a standard Langevin-type piezoelectric ultrasonic transducer mounted on a wave-guide with an aluminium concentrator, which amplifies the ultrasonic vibrations. 
The exact fixing used to attach a cutting tool to the vibrating concentrator is critical, since any additional mass added to the highly sensitive vibrating system will inevitably shift its resonating frequency (and affect its amplitude). Titanium, being light and mechanically strong, was chosen as an appropriate material for the tool holder. The customized tool holder was screwed into the tapped hole on the concentrator; the cutting tool was fixed to the tool holder with a standard high-tensile screw. Figure 1 shows a schematic of the cutting head, demonstrating its various parts that make up the ultrasonic cutting assembly. The assembly was fixed to the cross slide of the lathe by a specially designed tool-post attachment (Figure 2). Precautions were taken to ensure rigidity of the overall system at all fixing points. To measure cutting forces, the ultrasonic-head assembly was attached to a three-component Kistler ${ }^{\mathrm{TM}}$ dynamometer (model number 9257A). The dynamometer is capable of force measurements up to $5 \mathrm{kN}$ with a maximum frequency of $3 \mathrm{kHz}$, which was deemed adequate for measuring average cutting forces for the processes studied. The orientation of the dynamometer was chosen so that to measure cutting forces in the $x, y$ and $z$ directions corresponding to the tangential, radial and feed directions, respectively, in machining (Figure 2).

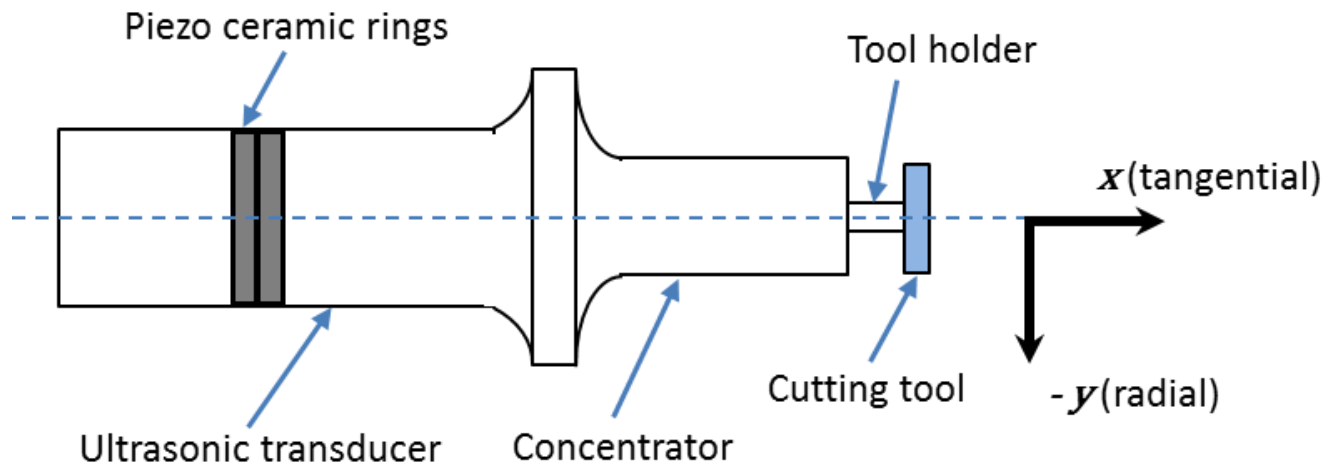

Figure 1: Schematic of ultrasonic cutting assembly (see also Fig. 2)

A Polytec laser vibrometer (model number OFV-3001) was used to monitor vibrations induced in the cutting tool during UAT. This non-contact measurement technique was used throughout the cutting process to ensure adequate resonance conditions of the cutting system after contact with the work- 
piece. It was observed that the resonating-frequency response of the system was sufficiently broad to be insensitive to small variations, which are inherent in cutting operations, even at the highest imposed depth of cut.

Setting a consistent depth of cut during machining is critical to ensure comparability of conventional and ultrasonically assisted processes. This was ensured with the use of a micrometric dial gauge that tracked the displacement of the cutting head within an accuracy of $\pm 10 \mu \mathrm{m}$ along with the lathe micrometer (Figure 2). Such a technique based on two independent settings and measuring methods for the depth of cut eliminates errors, which the lathe micrometer is susceptible to, especially in the sub-millimetre length scale due to inherent system compliance. The rotary speed of the work-piece was monitored via a laser tachometer with a resolution of $0.1 \mathrm{rpm}$.

These recent improvements that increased the overall stiffness of the UAT setup, by reducing fixingpoint compliance and increasing tool-post fixture rigidity, enhanced the system's performance, resulting in significant force reductions in UAM reported below (see Results).

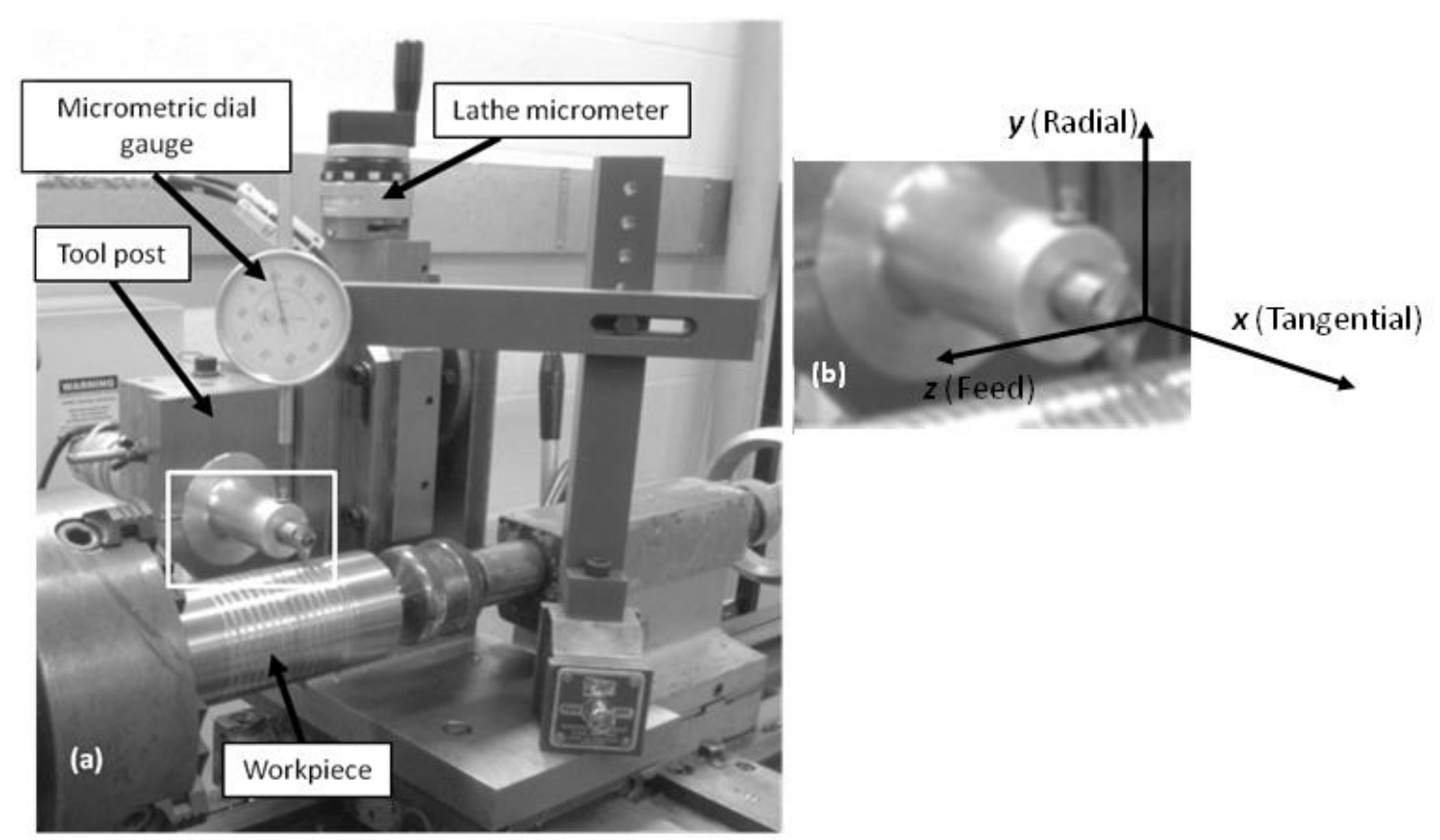

Figure 2: (a) Ultrasonic cutting assembly; (b) zoomed-in picture of cutting tool (marked with white box in (a)) showing axis alignment 


\subsection{Machine tool}

For our turning experiments, cemented-carbide tools were used with a nose radius of $0.8 \mathrm{~mm}$ with a low-depth-of-cut/finishing chip breaker optimized for low feed rates (Figure 3). The recommended cutting depth ranges from $0.2 \mathrm{~mm}$ to $3 \mathrm{~mm}$ with a feed rate of $0.05 \mathrm{~mm} / \mathrm{rev}$ to $0.25 \mathrm{~mm} / \mathrm{rev}$ and cutting speed of $45 \mathrm{~m} / \mathrm{min}$ (as specified by the manufacturer) in machining super-alloys. The tool material has a tough micro-grain structure suitable for intermittent cutting. The tool coating consists of a ceramic layer of titanium-aluminium nitride over a primer layer of titanium nitride. Addition of aluminium to the coating material leads to formation of an oxide layer, which, in turn, increases the tools ability to withstand high operating temperatures. Table 1 presents the properties of the cutting tool used. The tool was mounted orthogonal to the work-piece axis so that the effective rake angle was approximately $14^{\circ}$ and a clearance angle $0^{\circ}$.

Table 1: Cutting-tool specifications

Tool maker

SECO

Tool part number

DNMG 150608 MF1 CP500

Tool material

Micro-grain cemented carbide

Coating

$(\mathrm{Ti}, \mathrm{Al}) \mathrm{N}-\mathrm{TiN}$

Tool nose radius, $r_{c}(\mathrm{~mm})$

Nose angle $\left({ }^{\circ}\right)$

Cutting edge radius $(\mu \mathrm{m})$

Rake angle

$14^{\circ} 6^{\prime}$

Chamfer angle $\left({ }^{\circ}\right)$ 


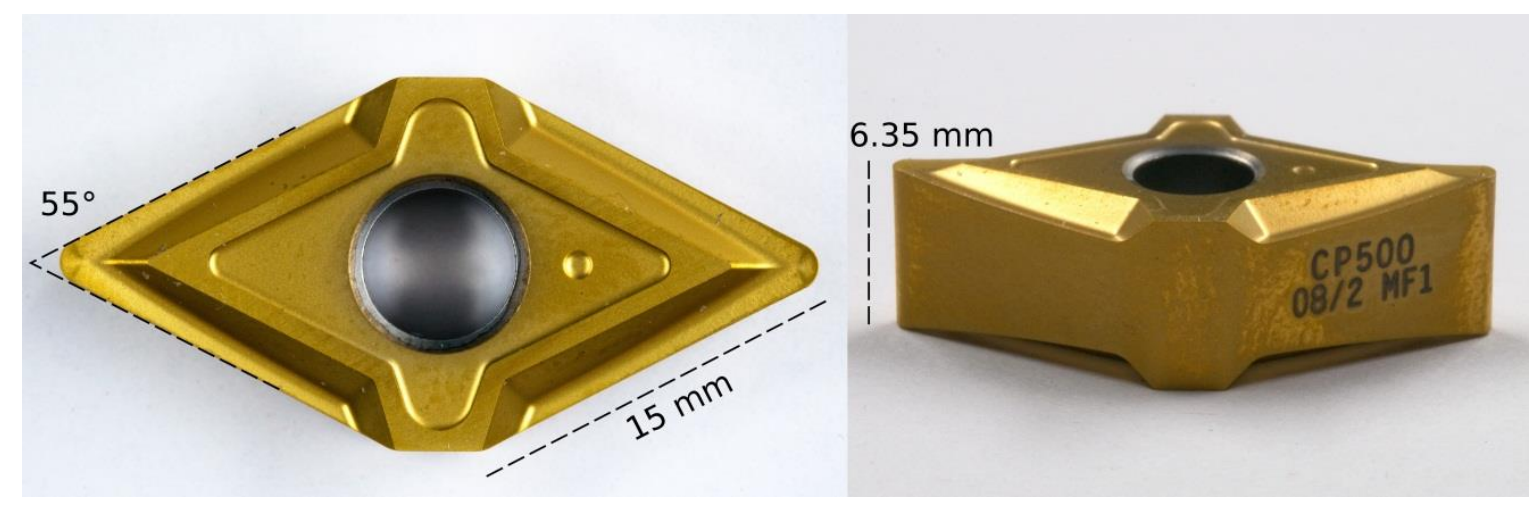

Figure 3: Cutting tool geometry

\subsection{Work-piece material}

The work-piece material used in the work belongs to a group of meta-stable $\beta$-Ti alloys, showing significant precipitation-hardening characteristics. The alloy is designated as Ti-15-3-3-3; it is solution-treated and aged by annealing at $790^{\circ} \mathrm{C}$ for 30 minutes followed by air cooling, resulting in the $\beta$-phase state. Mechanical properties of the work-piece material are listed in Table 2.

Table 2: Mechanical properties of work-piece material

\begin{tabular}{lr}
\hline Work-piece material & Ti-15V-3Al-3Cr-3Sn \\
Work-piece diameter, $D(\mathrm{~mm})$ & 80 \\
Producer & GfE Metalle and Materialien GmbH \\
Heat treatment & 87 \\
Young's modulus, $E(\mathrm{GPa})$, at room temperature & 4900 \\
Density, $\rho\left(\mathrm{kg} / \mathrm{m}^{3}\right)$ & 8.10 \\
Thermal conductivity, $k(\mathrm{~W} / \mathrm{Km})$ & 1200 \\
Ultimate tensile strength, $\sigma_{u l}(\mathrm{MPa})$ &
\end{tabular}

\subsection{Surface topography and sub-surface analysis}

To study surface topography of the machined work-piece, measurements were performed on a noncontact, three-dimensional, interferometry profiler ZYGO 3D-NV5000-5010. Nine sampling areas 
were evaluated on the machined surface; each sampling area having dimensions $0.53 \mathrm{~mm} \times 0.7 \mathrm{~mm}$. The data obtained was processed using the Taylor Hobson-Talymap Platinum 3D surface analysis software. Below several surface topography parameters are reported to compare and contrast the surface quality obtained with CT and UAT. Light microscopy of the subsurface layers was carried out on a Nikon Optiphot, with a GXCAM-5 acquiring system. Objective lens available on the machine varied from $\times 5$ to $\times 40$.

\subsection{Experimental Methodology}

Each experimental run lasted for approximately 60 seconds. Within the first 10 seconds the depth of cut was set to the desired magnitude followed by CT for 20 to 25 seconds (Figure 4). Next, the ultrasonic cutting head was switched on (with the machining continuing) for approximately 20 to 25 seconds before being switched off to recover CT cutting conditions. Between the two cutting processes there was a period of transient cutting conditions, which lasted for approximately 2 seconds; that was subsequently eliminated from the data analysis. Between experimental runs, the cutting tool was disengaged and allowed to cool to room temperature. This was done to ensure repeatability of experimental conditions for subsequent experimental runs. Ideally, a new tool should be used for each experimental run in order to circumvent the effect of tool wear on the machining process. For higher depth-of-cuts this was the case; however, for smaller depth-of-cuts tool wear was observed to be minimal and as such the cutting tool was replaced after 3 experimental runs without any detrimental consequences to the observed experimental characteristics. A detailed tool-wear analysis will be presented in the near future. Each experimental run was repeated 6 times to obtain reasonable statistics for our experimental data. The laser vibrometer was used throughout the entire cutting process. During UAT, we observed spurious vibrations in the radial and axial direction with amplitudes of approx. $1 \mu \mathrm{m}$ and $0.3 \mu \mathrm{m}$, respectively. This is not surprising as it is arduous to achieve a pure one-dimensional vibration system in transducer design and manufacture. The vibratory amplitude in the primary cutting direction 
(tangential direction) was observed to be $10 \mu \mathrm{m}$ for all the cutting depths. The cutting parameters used in our tests are listed in Table 3.

Table 3: Cutting parameters

\begin{tabular}{lr}
\hline Cutting speed, $V(\mathrm{~m} / \mathrm{min})$ & $10-70$ \\
Feed, $f(\mathrm{~mm} / \mathrm{rev})$ & 0.1 \\
Depth of cut, $a_{p}(\mu \mathrm{m})$ & $50-500$ \\
Vibration frequency, $f(\mathrm{kHz})$ & 17.9 \\
Tangential vibration amplitude, $a(\mu \mathrm{m})$ & 10 \\
Coolant & None \\
\hline
\end{tabular}

Superimposing ultrasonic vibration on the cutting tool has been shown to improve the surface finish of ductile as well as brittle materials with a concomitant reduction in cutting forces and machine chatter [23]. This was confirmed by recent studies by Maurotto et al. in both Ti-based [24] and Nibased alloys [25]. It should be noted that imposing tangential vibration (Figure 2) on the cutting tool in UAT changes the nature of the tool-work-piece interaction to an intermittent dynamic contact. From a 1-D analysis of tool-work-piece interaction conditions, a relation between the critical oscillatory speed of the tool $\left(v_{c}\right)$ and the speed of the work-piece motion $(V)$ can be derived for the UAT process to be effective. The critical tool speed and the cutting speed are related to the machining parameters [26] by

$$
\begin{aligned}
& v_{c}=2 \pi a f, \\
& V=\pi n D,
\end{aligned}
$$

where $n$ is the rotational speed of the lathe, $D$ is the work-piece diameter being machined, and $a$ and $f$ are the amplitude and frequency of the imposed vibration, respectively. For the machining 
parameters used, $v_{c}=67 \mathrm{~m} / \mathrm{min}$. It is expected that $v_{c}>V$ will ensure tool separation from the workpiece during a single vibratory cycle thus making UAT effective.

\section{Results}

In this section, we present the experimental results obtained with CT and UAT. We first report on the experimentally obtained averaged cutting forces followed by surface topology and sub-surface analysis of the machined work-piece.

\subsection{Cutting forces}

The cutting forces imposed on the tool were measured for CT and UAT performed with a varying depth of cut $\left(a_{p}\right)$. Depths of cuts ranging from $50 \mu \mathrm{m}$ to $500 \mu \mathrm{m}$ were set with varying increments of $50 \mu \mathrm{m}$ and $100 \mu \mathrm{m}$. A relatively low feed rate of $0.1 \mathrm{~mm} / \mathrm{rev}$ was set to emulate high precision machining, which typically deals with low material-removal rates (MRR) and, consequently, low feed rates.

The raw data acquired with the dynamometer via the attached picoscope, was processed in Matlab, without any filtering, to obtain average cutting forces. In the analysis, data from the initial engagement was eliminated (see Fig. 4). The dynamometer used has a natural frequency of $3 \mathrm{kHz}$; however, this was observed to shift significantly when additional mass/loads were imposed on it. The measured natural frequency of the cutting fixture, by a hammer impact test, was found to be $105 \mathrm{~Hz}$, far lower than the imposed frequency of the cutting tool. The highest sampling rate of the picoscope was $20 \mathrm{MHz}$, and a $1 \mathrm{MHz}$ acquisition frequency was used in our experiments, which was deemed sufficient for our requirements.

For all the experiments conducted the axial force component was measured to be smaller than the primary tangential cutting force and thus not considered in our analysis. Figure 4 shows a typical force measurement from our experimental procedure. The force component in the feed direction for both CT and UAT is observed to be lower in magnitude. Such a contribution can be explained 
primarily by the low imposed feed rate coupled with a large nose radius operating at low depth of cuts.

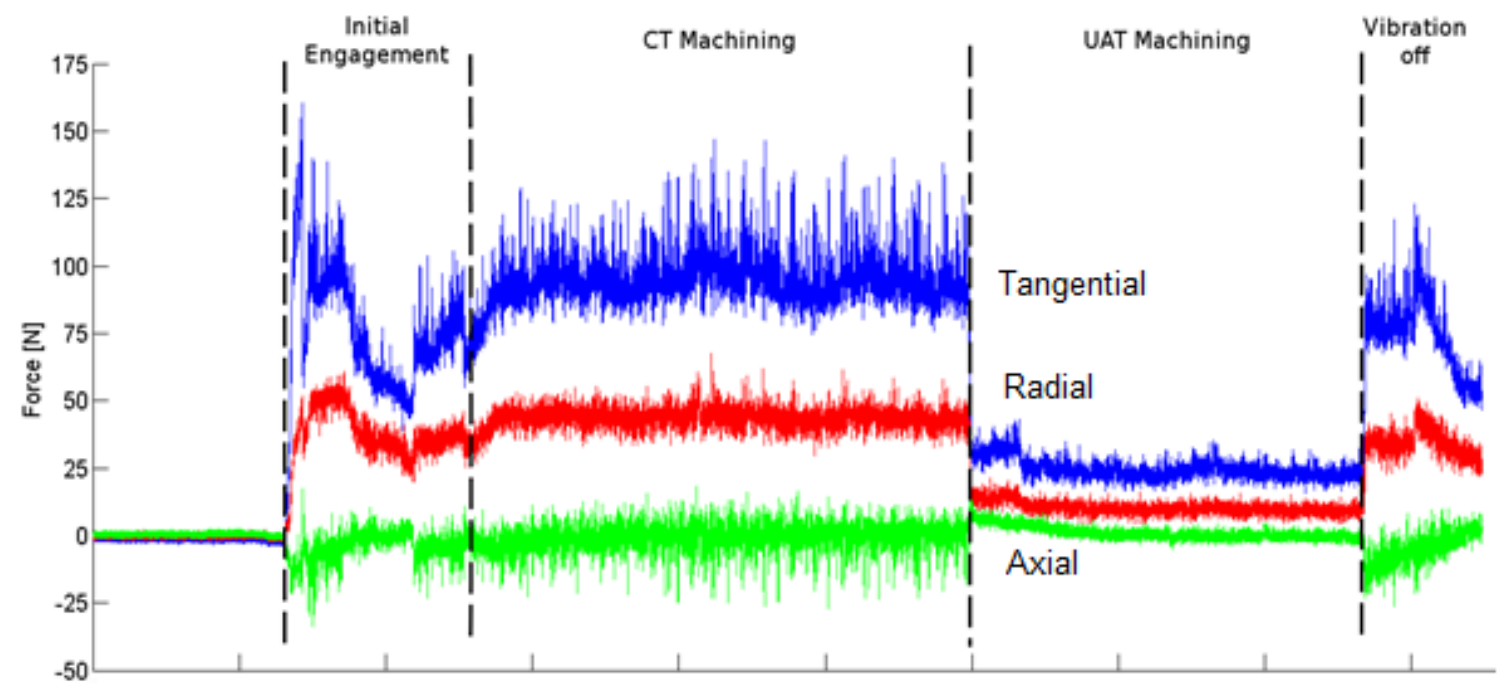

Figure 4: Evolution of force-component signals produced by dynamometer in single run. Machining parameters used: $V=10 \mathrm{~m} / \mathrm{min}, a_{p}=300 \mu \mathrm{m}, f=0.1 \mathrm{~mm} / \mathrm{rev}$. In UAT: $f=17.9 \mathrm{kHz}, a=10 \mu \mathrm{m}$.

The measured cutting force components at different levels of $a_{p}$ for both CT and UAT are presented in Figure 5. The diagram represents average values obtained from multiple machining runs, and the error bars indicate the standard deviation of the measured forces. Significant force reductions in the primary and radial cutting direction in UAT are observed for the entire studied range of $a_{p}$ (Table 4). 


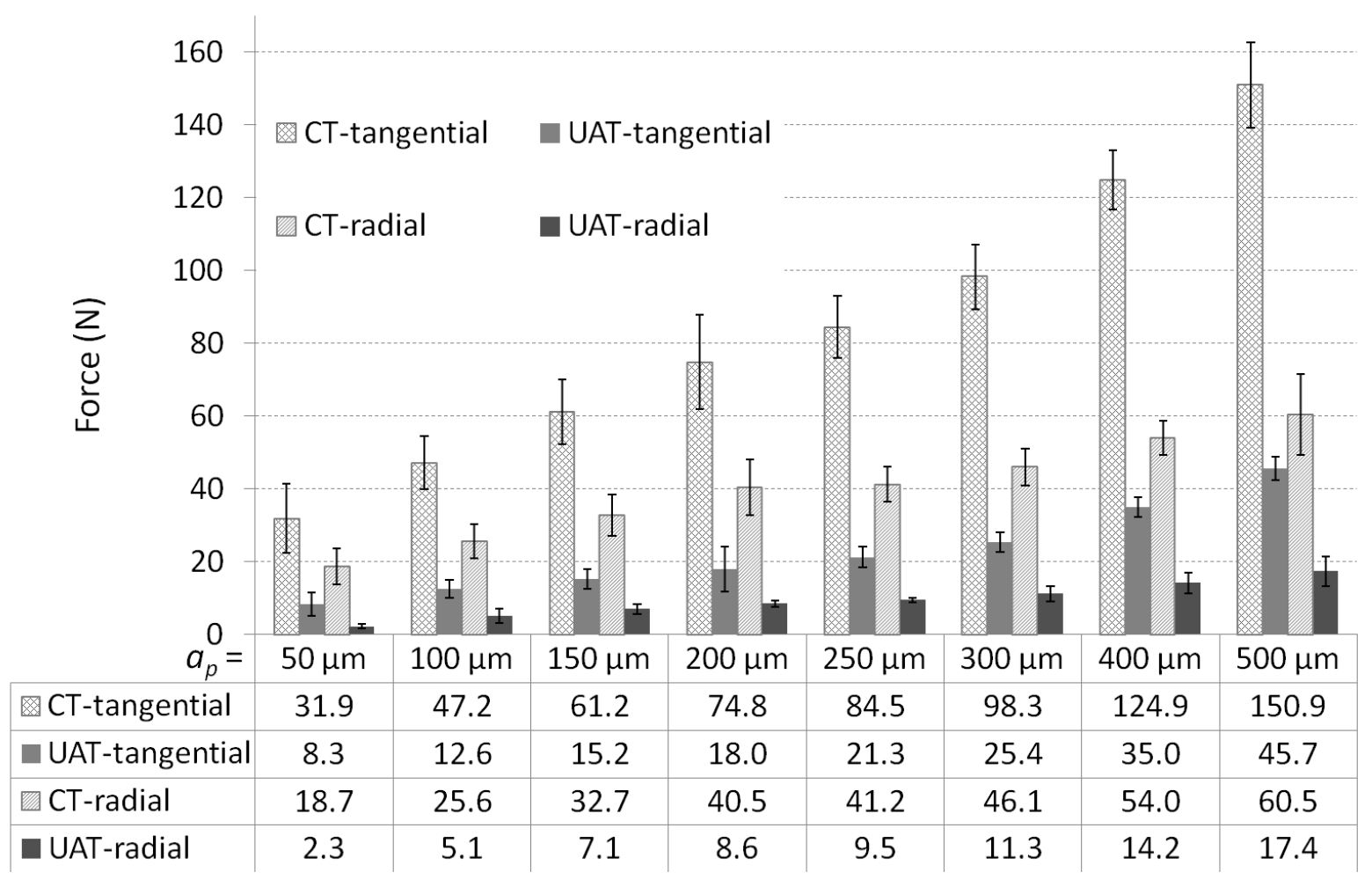

Figure 5: Cutting forces for CT and UAT at various depths of cut

Table 4: Measured cutting force reduction in UAT when compared to CT

\begin{tabular}{|ccc|}
\hline Depth of cut, $\boldsymbol{a}_{\boldsymbol{p}}(\boldsymbol{\mu \mathrm { m } )})$ & Tangential force reduction (\%) & Radial force reduction (\%) \\
\hline $\mathbf{5 0}$ & $\mathbf{7 4 \pm 6}$ & $88 \pm 3$ \\
\hline $\mathbf{1 0 0}$ & $73 \pm 5$ & $80 \pm 3$ \\
\hline $\mathbf{1 5 0}$ & $75 \pm 6$ & $78 \pm 4$ \\
\hline $\mathbf{2 0 0}$ & $76 \pm 10$ & $79 \pm 4$ \\
\hline $\mathbf{2 5 0}$ & $75 \pm 6$ & $77 \pm 3$ \\
\hline $\mathbf{3 0 0}$ & $74 \pm 6$ & $76 \pm 4$ \\
\hline $\mathbf{4 0 0}$ & $\mathbf{7 2 \pm 6}$ & $74 \pm 4$ \\
\hline $\mathbf{5 0 0}$ & $70 \pm 7$ & $71 \pm 8$ \\
\hline
\end{tabular}




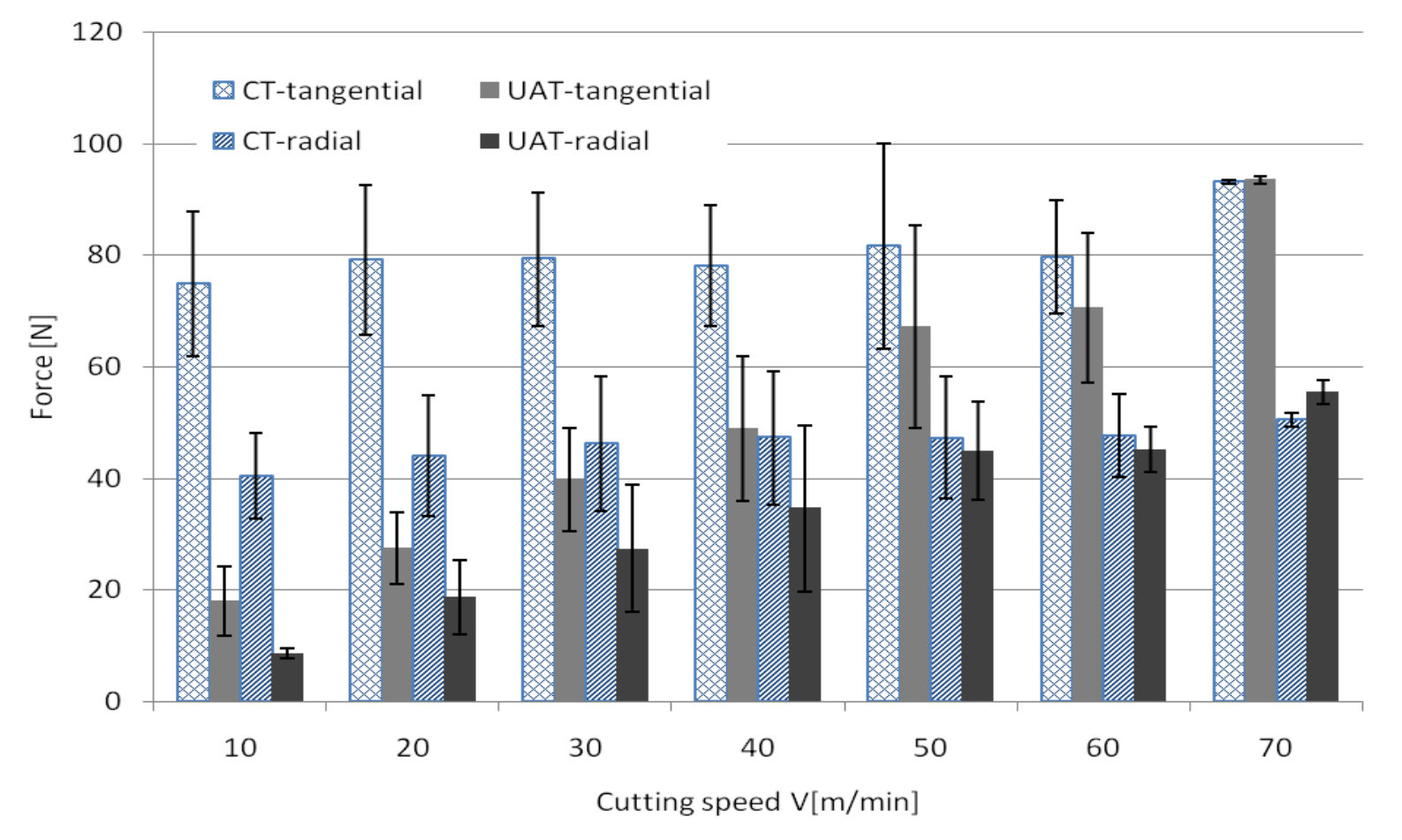

Figure 6: Cutting forces for $a_{p}=200 \mu \mathrm{m}$ in CT and UAT at various cutting speeds

The effect of cutting speed on the machining thrust forces was also investigated. Figure 6 shows the measured forces in CT and UAT averaged over 5 experimental runs for each value of cutting speed. Cutting forces in CT shows low sensitivity to the cutting speed within the studied range, as expected. However, in UAT cutting forces increased with increasing cutting speed causing a vanishing reduction in the level of cutting forces when UAT is compared to CT.

\subsection{Assessment of surface topography in machined components}

Characterisation of surface topography of the finished work-piece is essential in assessing machining quality. 


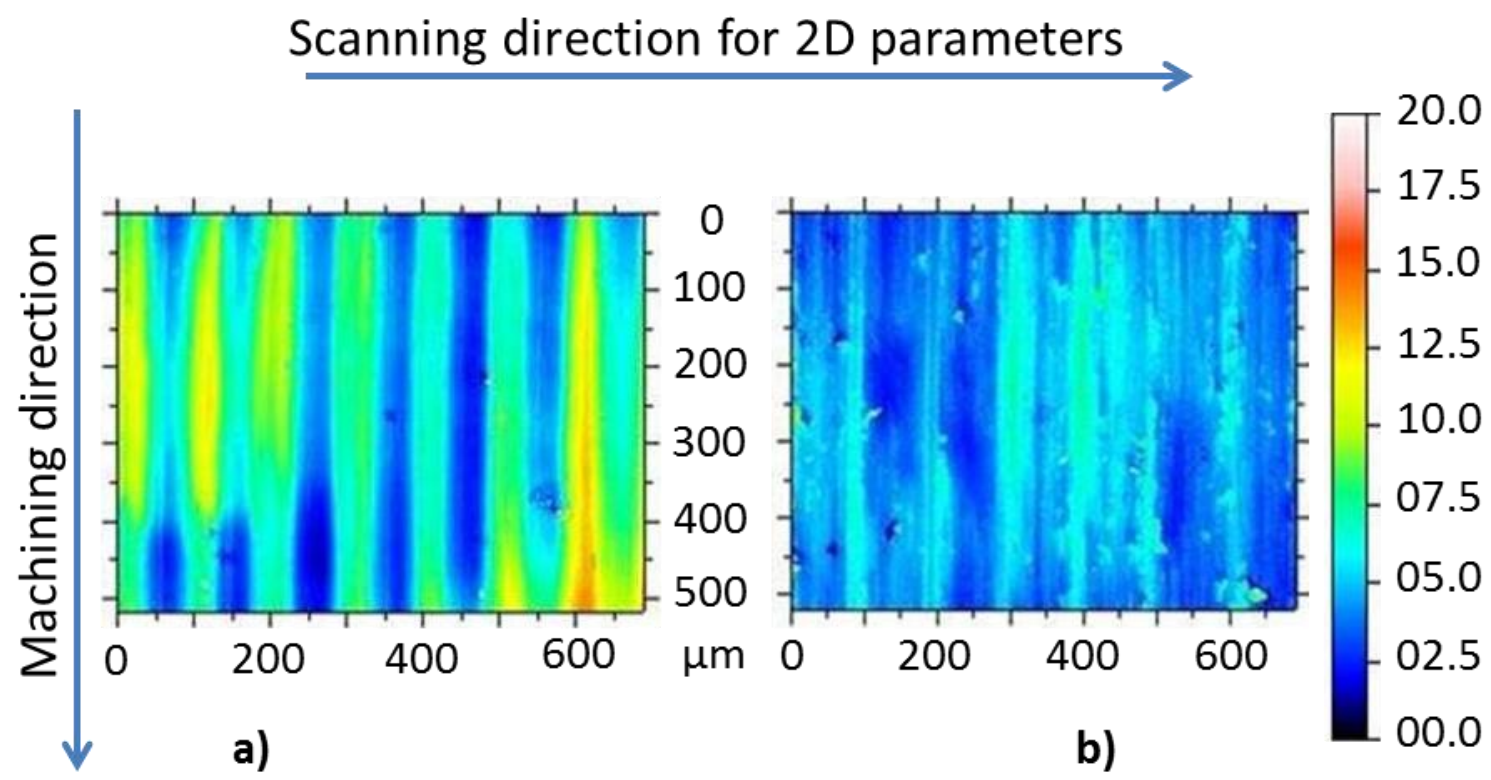

Figure 7: Interferometry scan on area of $0.53 \mathrm{~mm} \times 0.7 \mathrm{~mm}$ of surfaces machined with CT (a) and UAT (b)

In this section, results obtained for $a_{p}=200 \mu \mathrm{m}$ and $V=10 \mathrm{~m} / \mathrm{min}$ are presented. The result for this choice of cutting parameters are representative of all other depths of cut studied. Several key 2D and 3D parameters [27] to characterise the surface topography are interrogated. Figure 7 compares the underlying texture of typical surfaces machined with CT and UAT. These are represented as 2D field plots. Distinct periodicity can be observed for the conventionally turned surface whereas for the enhanced machining technique this regularity is somewhat curtailed. In CT the direction of tool path during machining is evident, with a periodicity of some $100 \mu \mathrm{m}$, corresponding to the imposed feed rate of $0.1 \mathrm{~mm} / \mathrm{rev}$ (Table 3).

The machined surface profiles were analysed employing various texture parameters quantified in Table 5. Amplitude parameters calculated from the roughness profile, such as $R_{a}$ and $R_{q}$ show a reduction of $49 \%$ and $41 \%$ in their levels, respectively, in UAT when compared to CT. This implies that within the measured sampling lengths the average roughness is significantly lower in UAT. 


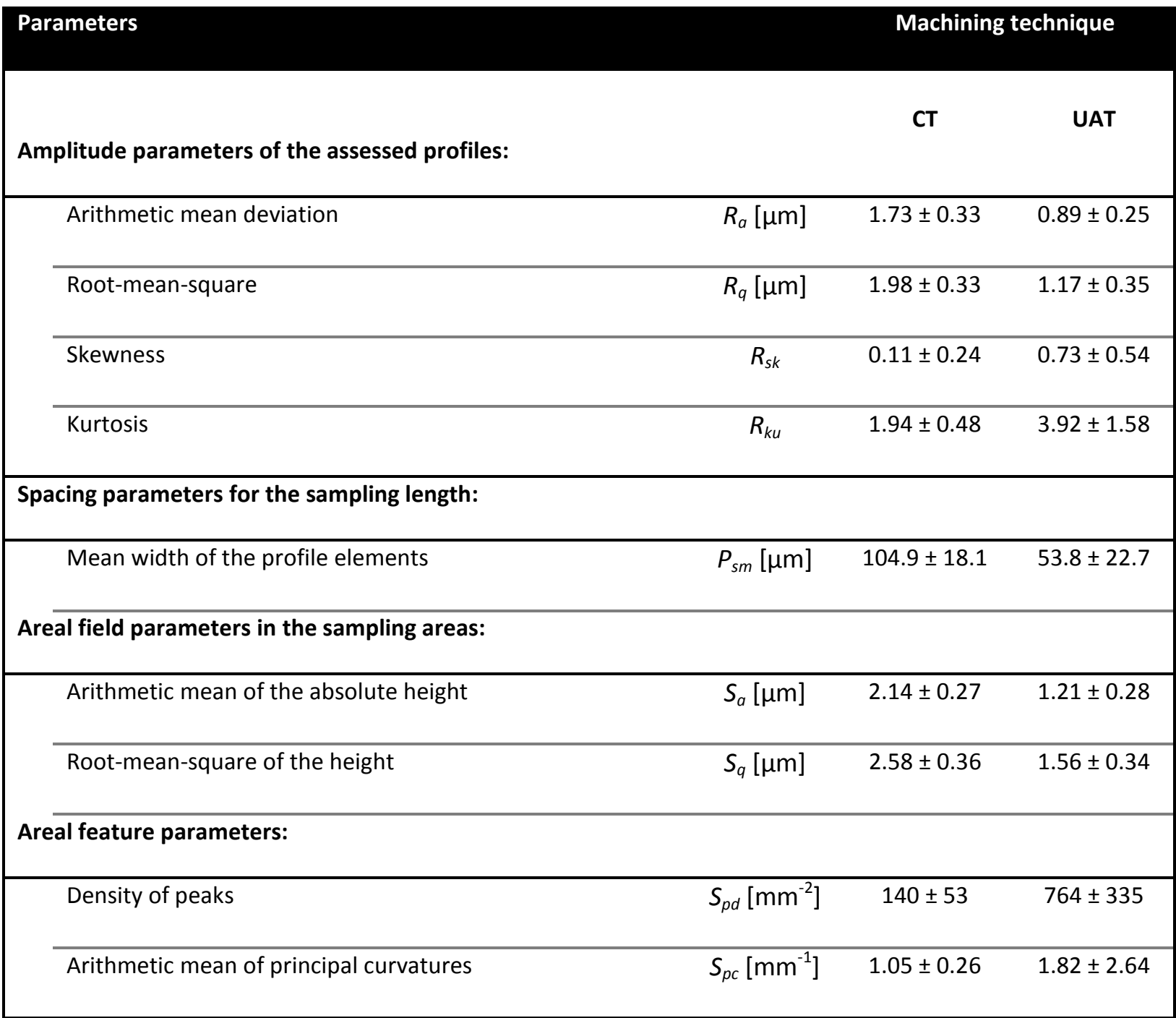

\subsection{Sub-surface analysis}

For the current study, sub-surface layers of work-pieces obtained with UAT and CT for machining conditions corresponding to $a_{p}=500 \mu \mathrm{m}$ were analysed. A higher $a_{p}$ inevitably leads to higher cutting forces and temperatures in the process zone during machining as demonstrated in the numerical studies $[19,28]$. Also, numerical models of UAT predict somewhat higher temperatures of the process zone when compared to CT for the same machining conditions [29]. Thus, analysis of the sub-surface layers obtained with UAT becomes crucial at such high depths of cut.

Cross-sections corresponding to CT and UAT were cut from the machined work-piece. Those were hot-mounted in acrylic resin and wet-polished to mirror finish using corundum papers of 
progressively increasing grit sizes. Final polishing was performed with the use of a colloidal $\mathrm{SiO}_{2}$ suspension with particle sizes of $2 \mathrm{~nm}$ in distilled water on a microfiber cloth. Next, the samples were etched using modified Kroll's reagent for $20 \mathrm{~s}$. Figure 8 compares the sub-surface microstructures for CT and UAT. The alloy presents a coarse grain structure with grains averaging $100 \mu \mathrm{m}$ in size. The images show no needle-like (alpha Ti) structures and no visible changes in the grain sizes for both UAT and CT when compared to a virgin work-piece sample (i.e. prior to machining (Fig. 8a). No visible changes are apparent in UAT for $a_{p}=500 \mu \mathrm{m}$. 

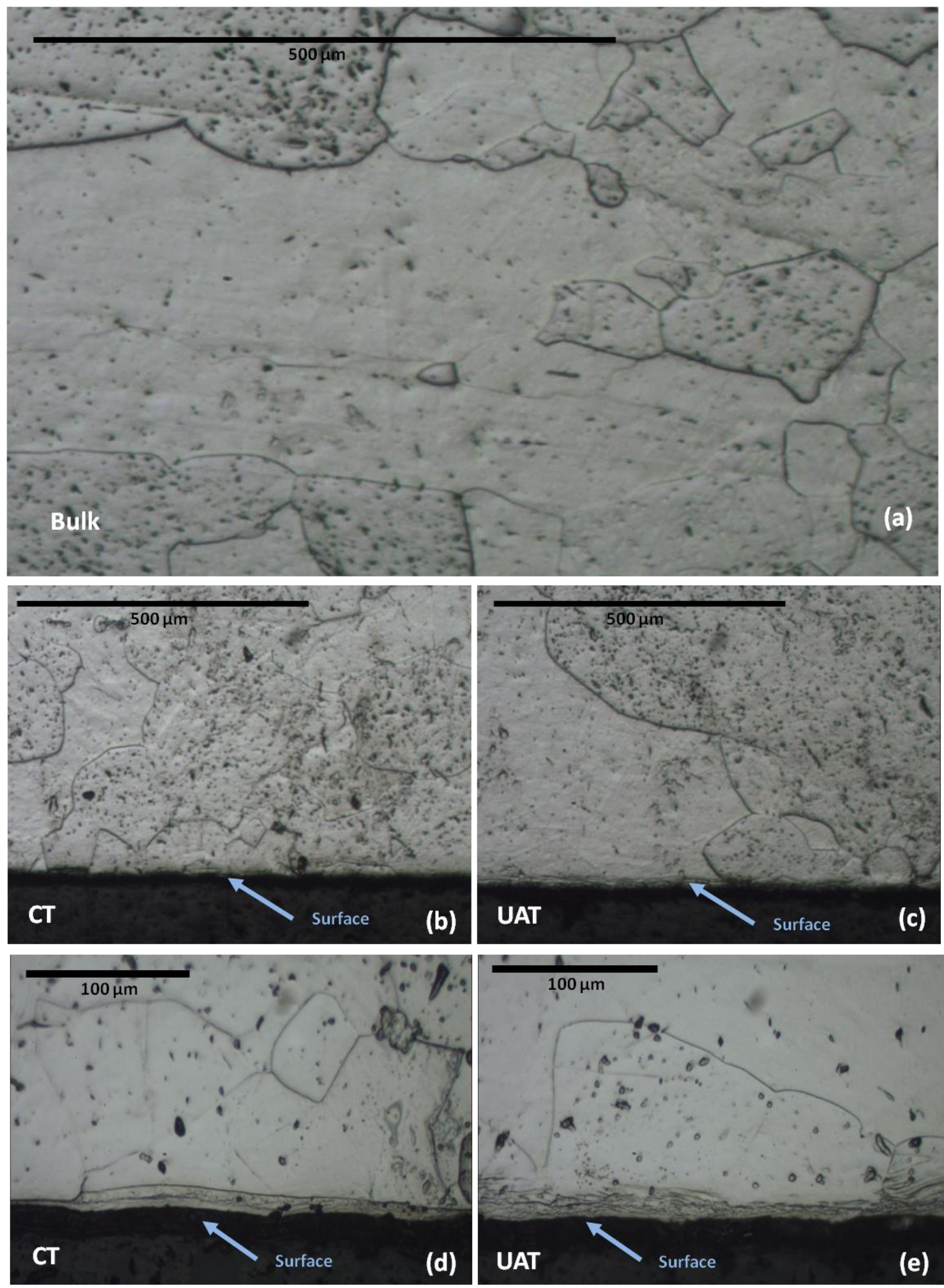

Figure 8. Etched cross sections of work-pieces: (a) virgin-state bulk sample; (b, d) machined with CT; (c, e) machined with UAT. Note different scales 


\section{Discussion}

Our previous machining experiments carried out with Inconel 718 , reported reductions in cutting forces of some $60 \%$ [30]. The setup used was similar to the one reported in this paper, albeit with several shortcomings with respect to its dynamical stability and the accurate setting of $a_{p}$. Though the main features of the current UAT system are similar to those of the previous experimental setup, its substantial improvements with respect to overall rigidity of the system allowed further reductions, often in excess of $80 \%$, in cutting forces (Table 4).

Typically, improvements in the tangential cutting forces are expected as these correspond to the primary direction (along the $X$-axis) of ultrasonic vibration imposed on the cutting tool. Highfrequency, low-amplitude vibration in the radial direction had also a noticeable effect on the measured cutting force components. The curvature of the work-piece allows for tool separation in the radial direction.

Mechanistic models of cutting typically ascertain specific cutting pressures, which indicate energy consumption associate with material removal. Figure 9 is a plot of the specific tangential cutting pressure, $S$, in CT and UAT at various depths of cut; the cutting speed was $10 \mathrm{~m} / \mathrm{min}$. Apparently, with increasing $a_{p}$ the cutting forces tend asymptotically to fixed levels. The force magnitudes for two analysed techniques are noticeably different at lower $a_{p}$. This is due to a ploughing effect during cutting due to the large tool nose radius. 


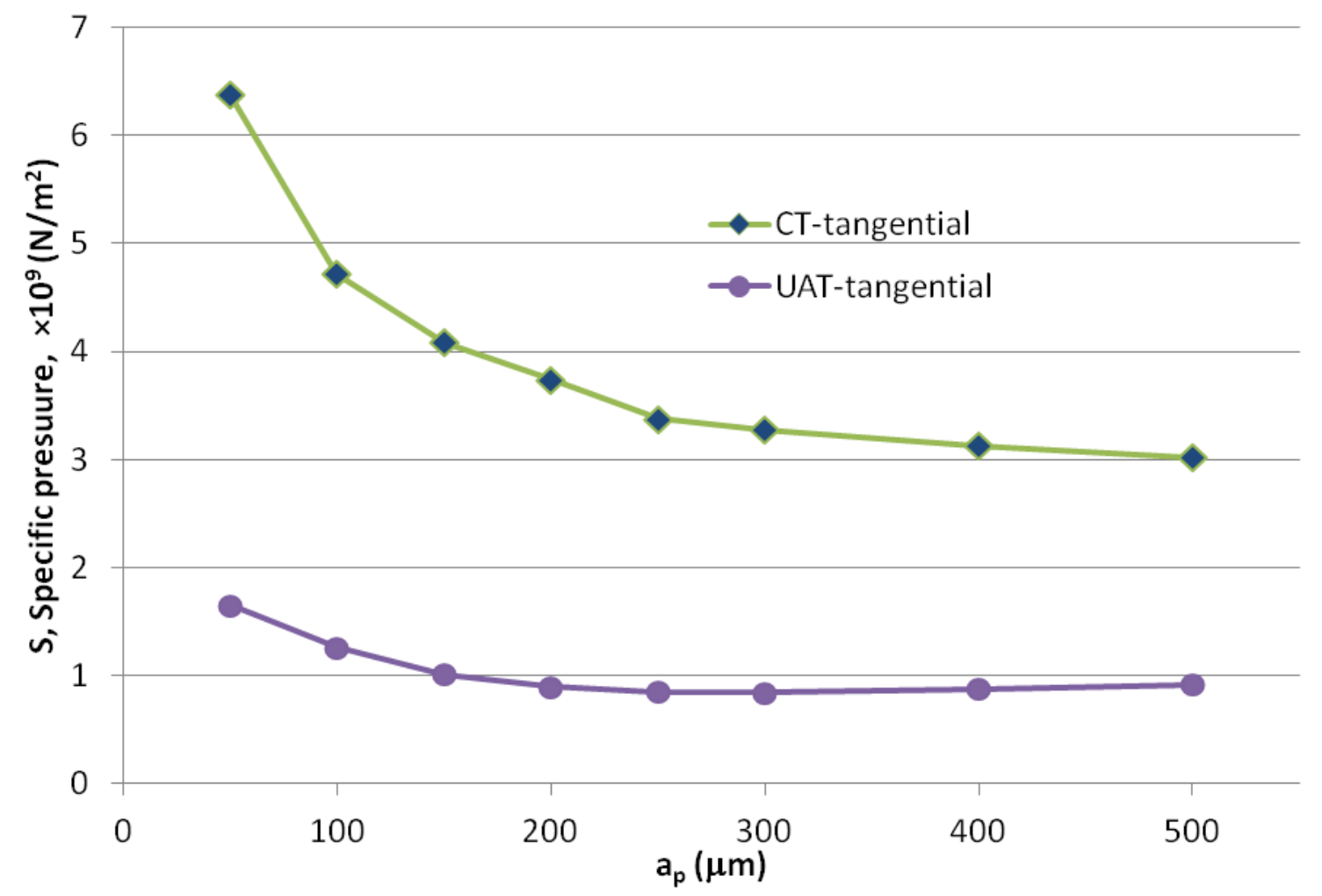

Figure 9.Specific cutting pressure at various cutting depths in CT and UAT at $V=10 \mathrm{~m} / \mathrm{min}$.

It is interesting to note that the average cutting forces in UAT for $a_{p}=500 \mu \mathrm{m}$ are comparable to those in CT for $a_{p}=150 \mu \mathrm{m}$ (see Fig. 5). This implies that, tool wear and tool life remaining the same in UAT, we can potentially increase the MRR during vibration assisted machining by a factor $>3$ (owing to the diamond shaped cutting tool geometry), with a cutting tool being exposed to the same level of cutting forces for respective cutting depths.

Surface topography studies (Table 5) demonstrate several interesting characteristics of the workpiece machined with UAT. In addition to the observed improvements in the amplitude parameters, the skewness parameter, $R_{s k}$ and the kurtosis parameter, $R_{k u}$, were assessed in order to assess the shape and sharpness of the height distribution. For UAT, a positive bias is observed $\left(R_{s k}>0\right.$, including statistical spread), which implies that there are relatively more peaks-to-valley transitions in the measured profile, with the overall profile tending to a spiky surface; we believe that this is a result of the micro-impact process which is inherent in UAT. Consequently, in CT, the profile shape tends to a skewness of zero (considering statistical spread) with $R_{k u}>3$ implying a symmetrical topography with 
a somewhat random and bumpy (less sharp) height distribution. The last two parameters $\left(R_{s k}\right.$ and $\left.R_{k u}\right)$ are useful in predicting component's performance with respect to wear and lubrication retention [27]. The obtained results indicate that UAT leads to improved lubrication retention in machined components. The spacing parameter, $P_{s m}$, indicates that in UAT the mean spacing between peaks or valleys is measurably smaller than $\mathrm{CT}$. In $\mathrm{CT}$, the influence of the imposed feed rate manifests in the measured $P_{s m}$ value of $0.1 \mathrm{~mm}$ (average). The low-amplitude axial vibration in UAT leads to a noticeably reduced value of $P_{s m}$. The multiple vibrations in UAT have a polishing effect on the machined work-piece surface.

The studied 2D profile parameters have inherent limitation with respect to characterisation of functional aspects of machined surfaces. Areal surface parameters are ideal for this purpose; it was observed that within the measured sampling area the areal height parameters $\left(S_{a}\right.$, and $\left.S_{q}\right)$ indicate that in UAT the surface departure of the measured profile abated significantly (by more than 40\%) when compared to CT. The areal feature parameters such as $S_{p d}$ and $S_{p c}$ confirm our observation that UAT leads to the generation of a large number of sharper peaks (albeit of significantly lower height) on the work-piece surface.

It is well known that conventional machining leads to high temperatures in the process zone and at the tool-work-piece interface. Coupled with the low thermal conductivity of the $\beta$-Ti alloy under study, it was imperative to analyse the sub-surface layer of the work-piece to check for phase transformations. Usually, high temperatures in $\beta-\mathrm{Ti}$ alloys lead to formation of $\alpha$-Ti phases that appear as needle-like structures under microscopy. These phases are particularly undesirable as they compromise the improved mechanical characteristics of the $\beta$ phase. Since no visible changes were observed in the UAT work-piece (Figure 8), it is safe to claim that no phase transformations are expected at studied depths of cuts and cutting speeds. Further SEM analysis will be carried out in the future to check for phase transformation, especially at higher cutting speeds. 


\section{Conclusions}

An improved UAT setup developed and tested for machining of a beta Ti alloy resulted in substantial reductions in the cutting forces, compared to conventional turning with the same cutting parameters. This was achieved with a concomitant improvement in the surface quality of machined specimens. The major conclusions of the study are as follows:

- Average cutting forces are observed to reduce in excess of $70 \%$ for depths of cut up to 0.5 $\mathrm{mm}$.

- Surface quality is observed to improve substantially in UAT.

- Ultrasonically assisted turning causes no adverse effects in the machined work-piece.

The data presented here are first results obtained with an improved UAM setup. Further studies of tool wear and overall tool life in UAT will be pursued in future. Even though UAT is a micro-chipping process, the initial observation demonstrated that the overall tool life was not seriously affected. It should be added, that special tools are required in vibration-assisted cutting, and the expectation of using conventional tools in UAT (as has been the case till now) is perhaps not appropriate due to totally different regimes of tool-workpiece interaction.

\section{Acknowledgement}

Funding from the European Union Seventh Framework Programme (FP7/2007-2013) under grant agreement No. PITN-GA-2008-211536, project MaMiNa, is gratefully acknowledged.

\section{References}

[1] P.J. Arrazola, A. Garay, L.M. Iriarte, M. Armendia, S. Marya, F. Le Maître, Machinability of titanium alloys (Ti6Al4V and Ti555.3). Journal of Materials Processing Technology 209 (2009), 22232230. 
[2] J. Sun, Y.B. Guo, A comprehensive experimental study on surface integrity by end milling Ti-6Al4V. Journal of Materials Processing Technology 209, (2009) 4036-4042.

[3] N. Zlatin, M. Field, Titanium. Titanium Science and Technology 1, (1973) 489-503.

[4] M.J. Donachie, Titanium- A Technical Guide, 2nd ed. ASM International, Ohio, 2004.

[5] T.H.C. Childs, K. Maekawa, T. Obikawa, and Y. Yamane, Metal Machining: Theory and Applications. John Wiley \& Sons, 2005.

[6] E.O. Ezugwu, J. Bonney, Y. Yamane, An overview of the machinability of aeroengine alloys. Journal of Materials Processing Technology 134, (2003) 233-253.

[7] F. Klocke, G. Eisenblätter, T. Krieg, Machining: Wear of Tools, 2nd ed. Encyclopaedia of Materials: Science and Technology, 2001.

[8] G. Byrne, E. Scholta, Environmentally clean machining processes - A strategic approach. CIRP Annals - Manufacturing Technology 42, (1993) 471-474.

[9] K. Weinert, I. Inasaki, J.W. Sutherland, T. Wakabayashi, Dry machining and minimum quantity lubrication. CIRP Annals - Manufacturing Technology 53, (2004) 511-537.

[10] P.T. Mativenga, M.F. Rajemi, Calculation of optimum cutting parameters based on minimum energy footprint. CIRP Annals - Manufacturing Technology 60, (2011) 149-152.

[11] C. Machai, D. Biermann, Machining of $\beta$-titanium-alloy Ti-10V-2Fe-3Al under cryogenic conditions: Cooling with carbon dioxide snow. Journal of Materials Processing Technology 211, (2011) 1175-1183.

[12] V.K. Astashev, V.I. Babitsky, Ultrasonic cutting as a nonlinear (vibro-impact) process. Ultrasonics 36 (1998), 89-96.

[13] B. Langenecker, Effects of ultrasound on deformation characteristics of metals, IEEE Transaction on Sonic and Ultrasonics. SU-13, No. 1, p. 1, (1966). Ultrasonics 4, V.

[14] W.P. Mason, Physical Acoustics and the Properties of Solids. Princeton, Van Nostrand, 1958.

[15] V.I. Babitsky, V.K. Astashev, A. Meadows, Vibration excitation and energy transfer during ultrasonically assisted drilling. Journal of Sound and Vibration 308, (2007) 805-814.

[16] V.I. Babitsky, A.V. Mitrofanov, V.V. Silberschmidt, Ultrasonically assisted turning of aviation materials: simulations and experimental study. Ultrasonics 42, (2004) 81-86.

[17] A. Sharman, P. Bowen, D. Aspinwall, and C. Dewes, Ultrasonic assisted turning of gamma titanium aluminide. Rolls-Royce PLC, 2001.

[18] J.D. Kim, I.H. Choi, Micro surface phenomenon of ductile cutting in the ultrasonic vibration cutting of optical plastics. Journal of Materials Processing Technology 68, (1997) 89-98.

[19] R. Muhammad, A. Maurotto, A. Roy, V.V. Silberschmidt, Analysis of forces in vibro-impact and hot vibro-impact turning of advanced alloys. Applied Mechanics and Materials 70, (2011) 315-320.

[20] N. Ahmed, A.V. Mitrofanov, V.I. Babitsky, V.V. Silberschmidt, 3D finite element analysis of ultrasonically assisted turning. Computational Materials Science 39, (2007) 149-154.

[21] H. Jamshidi, M.J. Nategh, Theoretical and experimental investigation of the frictional behavior of the tool-chip interface in ultrasonic-vibration assisted turning, International Journal of Machine Tools and Manufacture, 65, (2013), 1-7

[22] A. S. Adnan, S. Subbiah, Experimental investigation of transverse vibration-assisted orthogonal cutting of AL-2024, International Journal of Machine Tools and Manufacture, 50, 3, (2010), 294-302

[23] D. Brehl, T. Dow, Review of vibration-assisted machining. Precision Engineering 32, (2008) 153172.

[24] A. Maurotto, A. Roy, V. Babitsky, V.V. Silberschmidt. Recent developments in ultrasonically assisted machining of advanced alloys. in Proceedings of the 4th CIRP International Conference on High Performance Cutting (HPC2010), 24-26 October. 2010. Gifu, Japan. T. Aoyama, Y. Takeuchi (eds.), Vol. 2, pp. 81-84.

[25] A. Maurotto, A. Roy, V.I. Babitsky, V.V. Silberschmidt, Analysis of machinability of Ti- and Nibased alloys. Solid State Phenomena 188, (2012) 330-338.

[26] V.K. Astashev, V.I. Babitsky, Ultrasonic Processes and Machines: Dynamics, Control and Applications. SpringerVerlag, 2007. 
[27] R. Leach, Fundamental principles of engineering nano-metrology. Elsevier, Amsterdam, 2010.

[28] R. Muhammad, N. Ahmed, M. Demiral, A. Roy, V.V. Silberschmidt, Computational study of ultrasonically-assisted turning of Ti alloys. Advanced Materail Research 223, (2011) 30-36.

[29] A.V. Mitrofanov, V.I. Babitsky, V.V. Silberschmidt, Finite element simulations of ultrasonically assisted turning. Computational Materials Science 28, (2003) 645-653.

[30] A.V. Mitrofanov, V.I. Babitsky, V.V. Silberschmidt, Finite element analysis of ultrasonically assisted turning of Inconel 718. Journal of Materials Processing Technology 153-154, (2004) 233239. 